\title{
Naturally occurring aesculetin coumarin exerts antiproliferative effects in gastric cancer cells mediated via apoptotic cell death, cell cycle arrest and targeting PI3K/AKT/M-TOR signalling pathway
}

\author{
Jie Zhang ${ }^{1,2}$ Min Feng ${ }^{3}$ and Wenxian Guan 1,3区 \\ 'Department of General Surgery, Nanjing Drum Tower Hospital Clinical College of Nanjing Medical University, Nanjing, China; 2Department of \\ General Surgery, The Affiliated Hospital of Yangzhou University, Yangzhou, China; ${ }^{3}$ Department of General Surgery, Nanjing Drum Tower \\ Hospital, The Affiliated Hospital of Nanjing University Medical School, Nanjing, China
}

\begin{abstract}
Aesculetin is an active member of coumarins that has been reported to possess significant medicinal and biological importance. It has also been shown with potential anticancer activity against different human cancers including breast, lung and hepatocellular carcinoma. Therefore, the current investigation was undertaken to examine the anticancer effects of aesculetin against gastric cancer. MTT assay was performed to check the cellular viability and clonogenic assay was executed to assess the effect of aesculetin on colony formation capacity of SGC-7901 gastric cancer cells. Apoptosis was analysed by AO/EB staining and annexin V-FITC/PI staining assays. Cell cycle phases were monitored using flowcytometry and western blotting was used to detect the effects of aesculetin on PI3K/ AKT/M-TOR signalling pathway. Results indicated that aesculetin not only reduced the cellular proliferation in time-dependent manner but dose-dependent manner as well. Clonogenic tendency of SGC-7901 cells was retarded significantly by the aesculetin. The antiproliferative effects of aesculetin may arbitrate via apoptosis. Further, flow cytometric analysis revealed that the G2/M-phase SGC-7901 cells amplified number with increasing aesculetin doses. Indicating blocking of cell cycle at G2/M-phase. Finally, western blotting assay suggested blocking of PI3K/AKT/M-TOR signalling pathway by aesculetin in gastric cancer SGC-7901 cells. Taking altogether, aesculetin could induce significant growth inhibitory effects against gastric cancer SGC-7901 cells. Moreover, aesculetin could induce apoptotic cell death, cell cycle arrest and block PI3K/ AKT/M-TOR signalling pathway.
\end{abstract}

Keywords: Coumarins, gastric cancer, apoptosis, aesculetin, cell cycle Received: 26 August, 2020; revised: 13 October, 2020; accepted: 04 November, 2020; available on-line: 17 March, 2021

घe-mail: medguanwx@163.com

Abbreviations: AO/EB, acridine orange/ethidium bromide; DMSO dimethyl sulfoxide; MTT, 3-(4,5-dimethylthiazol-2-yl)-2,5-diphenyltetrazolium bromide; $\mathrm{PI}$, propidium iodide; $\mathrm{PI} 3 \mathrm{~K}$, phosphoinositide 3-kinase

\section{INTRODUCTION}

Coumarins are naturally occurring polyphenolic phytochemicals which show a structural moiety of fused benzene with $\alpha$-pyrone rings (Aoyama et al., 1992; Khursheed \& Vikrant, 2020). Till date, more than 1300 different coumarins have been recognised as secondary metabolites in fungi, bacteria and plants (Iranshahi et al., 2003). Due to huge structural diversity coumarins have been recognised with several biological and medicinal applications. Coumarins show neuroprotective, anti-inflammatory, antioxidant, antifungal, antibacterial, antiviral, anticonvulsant, antiadipogenic, antihyperglycemic, antitubercular and anticancer activity (Piller, 1975; Witaicenis et al., 2010; Hod'ak et al., 1967; Wang et al., 2009; Chain, 1958; Chiang et al., 2010; Shin et al., 2010). Coumarins have been shown to supress breast cancer, lung cancer, murine L1210, B16 melanoma and P388 leukemia (Yang et al., 2010; Portugal, 2013). Aesculetin is an active member of coumarins and has been reported to show several pharmacological and biological uses. Aesculetin has shown potential anticancer activity and inhibition of proliferation rate against gastric cancer, lung cancer, cervical cancer, oral cancer, prostate cancer, hepatocellular carcinoma and melanoma Noguchi et al., 1995; Wang et al., 2015). Aesculetin has been reported to target cancer cells via apoptosis, cell cycle, Wnt/ $\beta$-catenin signalling pathway, reactive oxygen species and mitochondrial mediated pathways. Gastric cancer is a leading malignancy with high frequency of mortality, globally. It has been ranked as second in cancer mortality and fourth in terms of disease prevalence. Near about one million patients are diagnosed with gastric cancer each year and in the year of 2012 around 0.8 million deaths were recorded of gastric cancer (Ferlay et al., 2013). Anatomically gastric cancer shows two variant subtypes including non-cardia gastric cancer (true gastric adenocarcinoma) and cardia gastric cancer (gastro-oesophageal junction adenocarcinoma). Among gastric cancer cases, true gastric adenocarcinoma is most common with approximately 0.7 million cases in the year of 2012 (Colquhoun et al., 2015). Gastric cancer burden remains very high on scientists and researchers despite of advancements made towards strategies, therapeutic options, molecular mechanisms, pathology and epidemiology. Therefore, there is an immediate need for novel therapeutics that can reduce gastric cancer related mortality and enhance overall survival rates. Herein, the current study was planned to explore the anticancer effects of aesculetin against human gastric cancer. The effects of apoptotic cell death, cell cycle arrest and targeting $\mathrm{PI} 3 \mathrm{~K} / \mathrm{AKT} / \mathrm{M}-\mathrm{TOR}$ signalling pathway by aesculetin were also investigated. 


\section{MATERIALS AND METHODS}

\section{Assessment of cell proliferation}

To analyse the viability of gastric SGC-7901 cancer cells after being exposed to aesculetin molecule, MTT assay was executed. In brief, gastric SGC-7901 cancer cells were precultured for $24 \mathrm{~h}$ within 96-well plates with $2.3 \times 10^{4}$ cells each well. Then each well plate was placed with variant aesculetin dose of $0,6,12,24,48$, and $96 \mu \mathrm{M}$, for $24 \mathrm{~h}$ and $48 \mathrm{~h}$ in a $5 \% \mathrm{CO}_{2}$ incubator containing $95 \%$ air at $37^{\circ} \mathrm{C}$. Aesculetin treatment was followed by addition of MTT stock solution $(200 \mu \mathrm{l})$ with concentration of $5 \mathrm{mg} / \mathrm{ml}$ in PBS for $4 \mathrm{~h}$ at $37^{\circ} \mathrm{C}$. Media was completely removed and cells were centrifuged for 5 minutes. Afterwards, formazan crystals are formed and dissolved in DMSO $200 \mu \mathrm{l}$ (Sigma, Aldrich). Finally, multiwell spectrophotometer (Immuno Reader (NJ-2000), Tokyo, Japan) was used to read absorbance at $540 \mathrm{~nm}$ and optical density was calculated.

\section{Colony detection assay}

To examine the potential of colony formation by gastric SGC-7901 cancer cells after being treated with aesculetin molecule, clonogenic assay was executed. In brief, gastric SGC-7901 cancer cells were placed with a concentration of 600 colonies per $6 \mathrm{~mm}$ diameter cultural dishes. Afterwards, each dish was subjected to aesculetin exposure at variant concentrations viz 0,12 , 48 and $96 \mu \mathrm{M}$, for $48 \mathrm{~h}$ with incubation. All the media was completely decanted and replaced with fresh one followed by incubation for further 14 days. SGC-7901 cell colonies were then fixed and stained with paraformaldehyde and crystal violet, respectively. The number of colonies were finally examined under a light microscope (Nikon, Japan) and colonies with size of $>0.5 \mathrm{~mm}$ diameter were considered for calculations.

\section{Apoptosis assay}

Apoptosis in aesculetin treated gastric SGC-7901 cancer cells was analyzed by $\mathrm{AO} / \mathrm{EB}$ staining assay and quantified with annexin V/PI staining assay. Briefly, SGC-7901 cells were placed onto 96-well plates with a density of $1.5 \times 10^{4}$ cells followed trypsinisation with $0.25 \%$ trypsin. Variant aesculetin concentrations viz 0 , 12, 48 and $96 \mu \mathrm{M}$ were loaded to each well and left on incubation for $24 \mathrm{~h}$. SGC-7901 cells were again trypsinized and loaded onto glass slides. Each slide was enclosed with coverslips after being stained with $100 \mathrm{mg} /$ $\mathrm{ml}$ of $\mathrm{AO} / \mathrm{EB}$ staining solution. Finally, a fluorescent microscope (OYMPUS, Japan) was used to visualise the apoptotic morphology of SGC-7901 cells.

\section{Annexin V-FITC/PI staining assay}

To determine the extent of apoptosis in gastric cancer SGC-7901 cells after aesculetin treatment, flow cytometric analysis was implemented using annexin $\mathrm{V} / \mathrm{PI}$ dual staining. Briefly, gastric cancer SGC-7901 cells were harvested at $85 \%$ confluency and then subjected to aesculetin $(0,12,48$ and $96 \mu \mathrm{M})$ treatment for $24 \mathrm{~h}$ in 6-well plates. Afterwards, aesculetin treated cells were subjected to washing using PBS thrice. Following washing, annexin V-FITC/PI staining solution (cat. no. CA1020, Solarbio, China) was added to the cells with 10 minutes of incubation at room temperature. Finally, BD Accuri ${ }^{\mathrm{TM}}$ C6 flow cytometer (BD Biosciences, NJ, United States) was used to detect the apoptotic cell percentage.

\section{Cell cycle analysis}

Modifications in the phases of cell cycle in aesculetin treated gastric cancer SGC-7901 cells were assessed by flow cytometry. In brief, SGC-7901 cells with a concentration of $1 \times 10^{6}$ cells/well were subjected to aesculetin exposure at variant doses of $0,12,48$ and $96 \mu \mathrm{M}$ for $48 \mathrm{~h}$ in 6 -well plates (well diameter $=34.8 \mathrm{~mm}$ with $16.8 \mathrm{ml}$ well volume). Afterwards, cells were collected and subjected to PI $(10 \mu \mathrm{g} / \mathrm{ml})$ staining. Finally, the different phases of cell cycle were examined through FACS Scan flow cytometer (BD Biosciences, Germany).

\section{Western blotting assay}

To assess the activity of various proteins in gastric cancer SGC-7901 cells, western blotting assay was implemented. Briefly, cells were harvested at logarithmic phase of growth and then treated with variant aesculetin doses viz $0,12,48$ and $96 \mu \mathrm{M}$ for $48 \mathrm{~h}$ in 6-well plates. Afterwards, aesculetin infected SGC-7901 cells were lysed involving a lysis buffer. Each lysate was forwarded for BCA assay to determine protein quantity. $40 \mu \mathrm{g}$ from each lysate was separated using SDSPAGE and finally transferred electrophoretically on nitrocellulose membranes. Skimmed milk was used for membrane blocking followed by primary antibody treatment overnight at $4^{\circ} \mathrm{C}$. Primary antibodies were used against m-TOR, AKT and PI3K. Afterwards, secondary HRP-conjugated antibody treatment was instigated and finally Super Signal West-Femto reagent (Pierce, Rockford, IL, USA) was used to detect signals.

\section{Statistical analysis}

All the experimental data obtained from individual triplicate experiments was subjected to Duncan's multiple range tests for comparisons and analyzed through one-way ANOVA. Considering $p<0.05$ as statistically significant, all the data was expressed as \pm S.D.

\section{RESULTS}

\section{Proliferation suppression by aesculetin in SGC-7901 cells}

Proliferation rate was monitored in aesculetin treated SGC-7901 cells by MTT assay (Fig. 1). Cancer cells multiply at a rapid pace and this feature is prominent in all types of cancer. Therefore, targeting cancer cell proliferation is a powerful strategy against cancer. Results from the MTT assay indicate that the aesculetin inhibited the proliferation rate time as well as dose dependently. The proliferation percentage at controls was taken as $100 \%$, post aesculetin treatment $(0-$ $96 \mu \mathrm{M})$ proliferation reduced significantly from 100\% to almost $20 \%$ after $24 \mathrm{~h}$ of treatment. After $48 \mathrm{~h}$ of treatment viability was observed to be limited to $5 \%$ (Fig. 2). Therefore, aesculetin could potentially inhibit the proliferation of SGC-7901 cells.<smiles>O=c1ccc2cc(O)c(O)cc2o1</smiles>

Figure 1. Chemical structure of aesculetin molecule. 


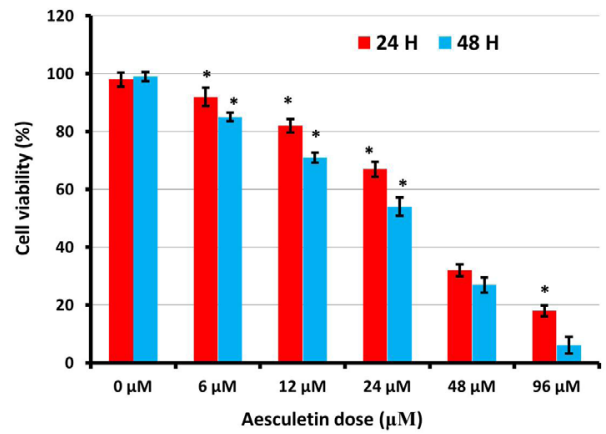

Figure 2. Graphical representation of results from MTT assay indicating inhibition of viability after aesculetin treatment. Cells were precultured for $24 \mathrm{~h}$ and then treated with indicated doses of aesculetin for further $24 \mathrm{~h}$. The cell viability of the control is taken as $100 \%$ cell viability and the viability of the treated cells is compared with the control cells. Every single experiment was repeated in triplicates with taking $p<0.05$ as statistically significant. All the data was presented as \pm S.D.
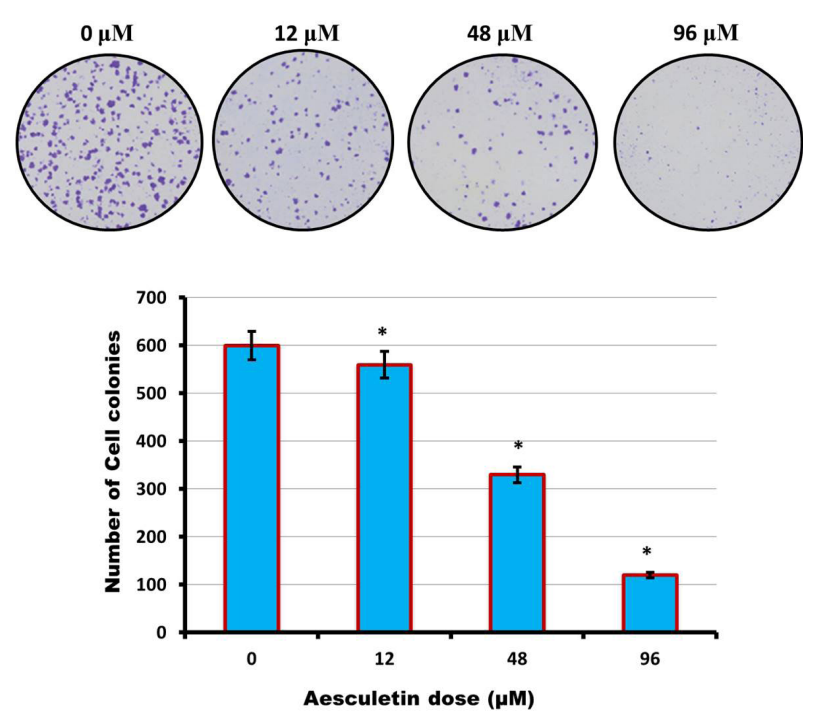

Figure 3A. Results representing cultural dishes with gastric cancer SGC-7901 cell colonies after aesculetin exposure for 14days. Every single experiment was repeated in triplicates.

Figure 3B. Graphical representation of results from clonogenic assay presenting reduced number of cell colonies in aesculetin treated SGC-7901 cells at indicated doses.

Every single experiment was repeated in triplicates with taking $p<0.05$ as statistically significant. All the data was presented as \pm S.D.

\section{Suppression of SGC-7901 colonies by aesculetin}

To determine the impact of aesculetin on clonogenic capability of gastric cancer SGC-7901 cells, a clonogenic assay was performed. After exposing target cells to aesculetin at variant concentrations $0-96 \mu \mathrm{M}$ for 14 days, the results showed tremendous colony suppression of SGC-7901 cells (Fig. 3A). The number of colonies in control group was counted to be 600 and after the cells were treated with variant aesculetin concentrations, the cell number reduced significantly (Fig. 3B).

\section{Aesculetin induced apoptosis in SGC-7901 cells}

The antiproliferative effects of aesculetin were testified for apoptosis mediation to unearth the underlying mechanism. For apoptosis analysis annexin V-FITC and $\mathrm{AO} / \mathrm{EB}$ staining assay was used. Results from the fluorescence microscopy indicated changes in the
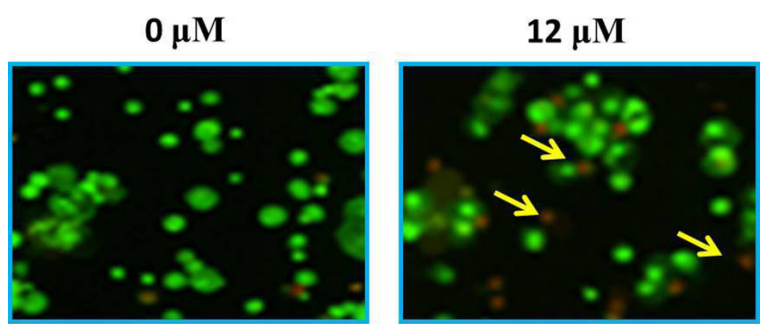

$48 \mu \mathrm{M}$

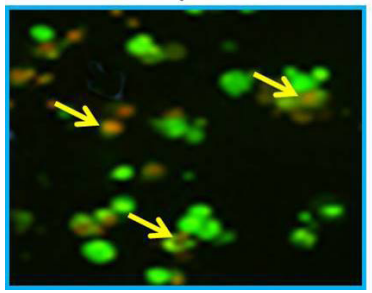

$96 \mu \mathrm{M}$

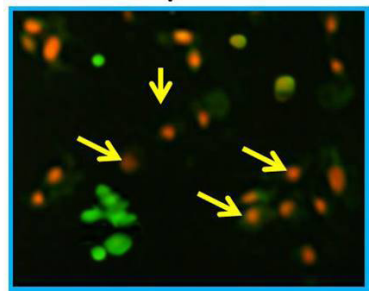

Figure 4. Apoptosis analysis through AO/EB staining assay indicating apoptotic cells (early stage and late stage) and necrotic cells after exposure to indicated aesculetin doses.

Every single experiment was repeated in triplicates

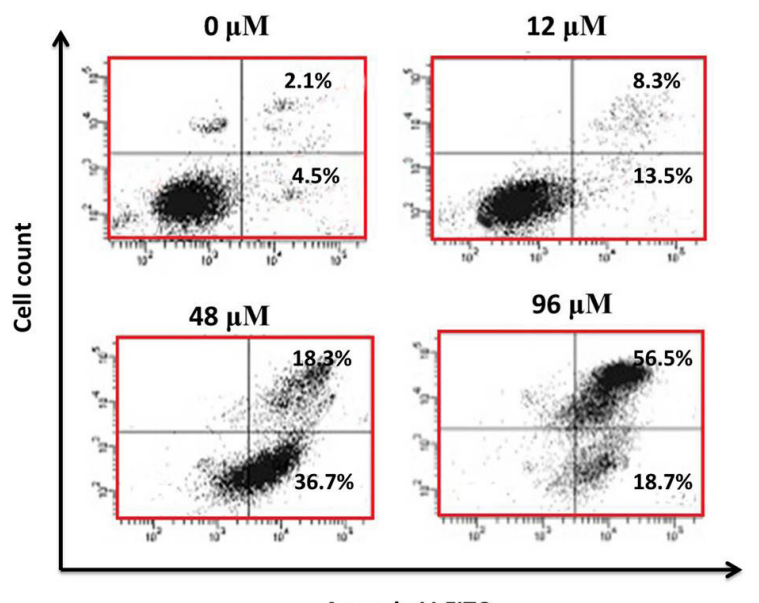

Annexin V-FITC

Figure 5. Apoptosis quantification through annexin V-FITC/PI staining assay indicating apoptotic cells (early stage and late stage) and necrotic cells after exposure to indicated aesculetin doses.

Every single experiment was repeated in triplicates with taking $p<0.05$ as statistically significant. All the data was presented as \pm S.D.

structure of aesculetin treated SGC-7901 cells in contrast to controls that indicated apoptosis. The number of apoptotic cells (early and late stage) and necrotic cells was monitored to enhance with enhanced doses of aesculetin (Fig. 4). Annexin V-FITC/PI staining assay outcomes indicated that the apoptotic cell percentage amplified from $6 \%$ to $75 \%$ after exposure to higher doses of aesculetin (Fig. 5). Therefore, annexin V-FITC/PI staining results indicated that the antiproliferative effects of aesculetin could be of its apoptosis inducing potency.

\section{Aesculetin targeted cell cycle in SGC-7901 cells}

Cell cycle phases were assessed via flow cytometric examination of aesculetin treated SGC-7901 cells. Results indicated that aesculetin could induce dose-reliant inhibitory effects on G2/M-phase of SGC-7901 cell cycle. The number of G2/M-phase cells amplified from about $20 \%$ 


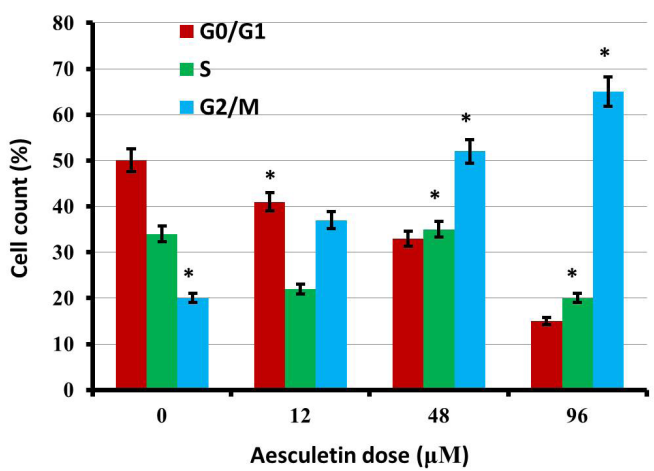

Figure 6. Flow cytometric analysis representing different phases of cell cycle after being subjected to aesculetin.

Every single experiment was repeated in triplicates with taking $p<0.05$ as statistically significant. All the data was presented as \pm S.D.

to nearly $65 \%$ in comparison to $\mathrm{S}$ and G0/G1 cell cycle phases (Fig. 6).

\section{Aesculetin targeted the PI3K/AKT/M-TOR signalling pathway}

Western blotting assay was performed to check the activity of $\mathrm{PI} 3 \mathrm{~K} / \mathrm{AKT} / \mathrm{M}-\mathrm{TOR}$ signalling pathway allied proteins. PI KK/AKT/M-TOR signalling pathway is among the pivotal pathways that operate to maintain normal growth and differentiation in a cancer cell. Targeting it leads to desirable results for the cancer researchers. After SGC-7901 cells were exposed to aesculetin molecule, cells were lysed to quantify protein content. It was observed that the activity of $\mathrm{m}$ TOR and AKT remained almost unchanged and that of p-mTOR, p-AKT, p-PI3k and PI3K, reduced significantly (Fig. 7A). Therefore, western blotting supported the fact that aesculetin blocked the PI3K/AKT/M-TOR signalling pathway in gastric cancer SGC-7901 cells. The quantified results of the western blot were obtained by densitometry and are shown in Fig. 7B, 7C and 7D.

\section{DISCUSSION}

Gastric cancer is a global health burden on researchers and scientists due to late diagnosis, low survival rates, lack of potential treatment methodologies and chemotherapeutics (Janunger et al., 2001). Several therapeutic targets in cancer cells have been recognised including apoptosis, autophagy, cell cycle, cell survival pathways etc. Continuously, researches search for novel targets which can provide with better results. Apoptosis is a phenomenon of cell death, which activates to discard the old, injured, and malfunctioning cells (Piao et al., 2001; Pu et al., 2002). Therefore, apoptosis is referred to as programmed cell death. Apoptosis remains a major therapeutic target of chemopreventives as it is stimulated by a number of factors and reaction cascade (Chao et al., 2004). Bax protein expression in a cell is enhanced when apoptosis takes place, and the expression of $\mathrm{Bcl}-2$ protein gets retarded. Therefore, Bax is termed as pro-apoptotic and $\mathrm{Bcl}-2$ is termed as anti-apoptotic protein (Jeon et al., 2015; Wall et al., 2003). Apoptosis is either mitochondrial mediated or death receptor mediated process, the former one is known as intrinsic and the latter as extrinsic pathway. Cancer cell frequently proliferates in an uncontrolled manner and result in fast tumor development. Thus, targeting cell cycle in a cancer results in suppression of carcinogenesis and tumour growth (Hsu et al., 2001). In addition to this, several growth and differentiation regulatory processes are involved in maintenance of carcinogenesis like that of PI3K/AKT/M-TOR signalling pathway (Hara et al., 2005). Herein, the anticancer expression of aesculetin was monitored against human gastric cancer SGC-7901 cell line. An attempt was also made to uncover its underlying mechanism through investigation of apoptosis, cell cycle and PI3K/ AKT/M-TOR signalling pathway. The outcomes of the current investigation indicated that aesculetin could induce antiproliferative effects on gastric SGC-7901 cancer cell line in a dose along with time-reliant manner. In addition to this, clonogenic potential of SGC-7901 reduced significantly after being exposed to aesculetin molecule.

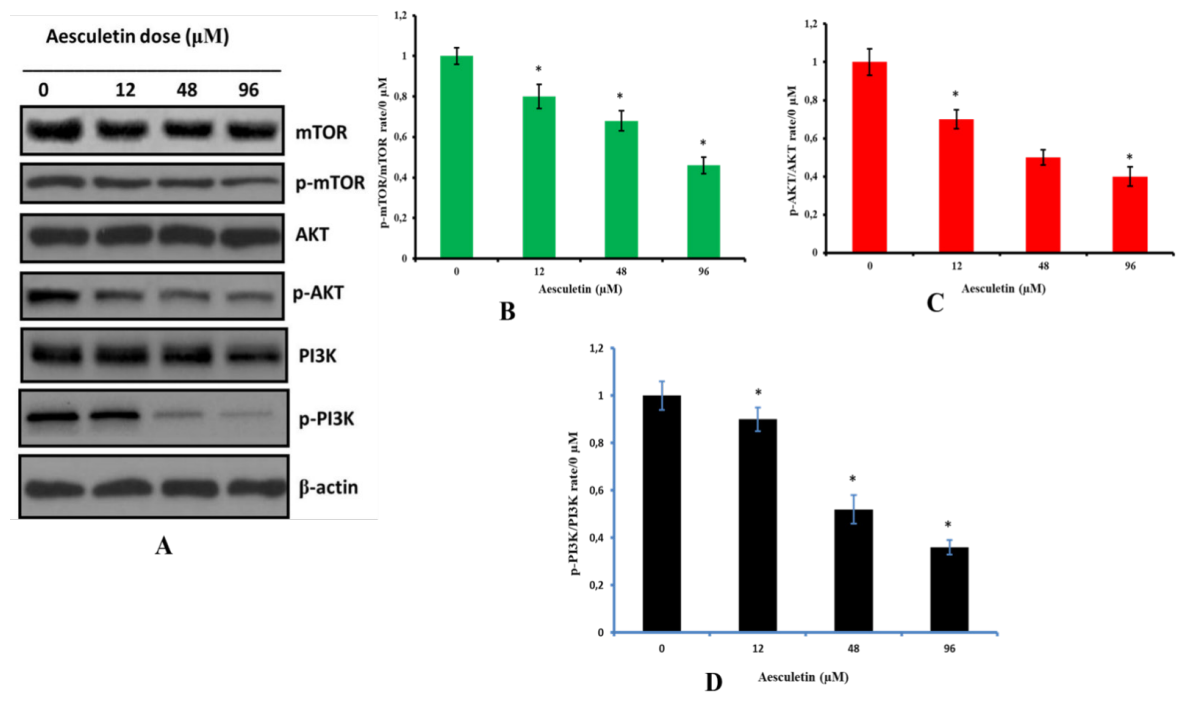

Figure 7A. Western blotting assay results representing the expression of mTOR/PI3K/AKT signalling pathway allied proteins. SGC7901 cells were exposed to variant doses of aesculetin for $24 \mathrm{~h}$. Every experiment was repeated in triplicates. Figure 7B. Statistical analysis of p-mTOR and total mTOR expression in SGC-7901 cells following treatment with the indicated concentrations of aesculetin; ${ }^{*} p<0.01$ compared with the $0 \mu \mathrm{M}$ control group. Figure 7C. Statistical analysis of $p$-AKT and total AKT expression in SGC-7901 cells following treatment with various concentrations of aesculetin; ${ }^{*} p<0.01$ compared with the $0 \mu M$ control group. Figure $7 D$. Statistical analysis of p-PI3K and total PI3K expression in SGC-7901 cells following treatment with the indicated concentrations of aesculetin for $24 \mathrm{~h}$. ${ }^{*} p<0.01$ compared with the $0 \mu \mathrm{M}$ control group. The quantified results were obtained using densitometry. 
Therefore, an attempt was made to unearth the underlying mechanism of action behind antiproliferative effects of aesculetin. AO/EB staining assay and Annexin V/PI staining assay was used to investigate apoptosis in SGC7901 cells indicating apoptotic cell death. Further, aesculetin could target cell cycle in SGC-7901 cells resulting in cell cycle arrest at G2/M-phase of cell cycle. Finally, the effect of aesculetin on PI3K/AKT/M-TOR signalling pathway was examined and results showed inhibition of the pathway supressing the expressions of phosphorylated forms of these proteins.

\section{CONCLUSION}

Results of the current in vitro investigation indicate remarkable anticancer effects of aesculetin coumarin against gastric cancer. The anticancer nature of aesculetin was assessed to mediate via apoptotic cell death, cell cycle arrest and targeting PI $3 \mathrm{~K} / \mathrm{AK} \mathrm{T} / \mathrm{M}-\mathrm{TOR}$ signalling pathway. Therefore, aesculetin may prove a lead molecule in gastric cancer research provided more in vitro and in vivo studies are carried out.

\section{Conflict of interest}

The authors declare that there is no conflict of interest to indicate.

\section{REFERENCES}

Aoyama Y, Katayama T, Yamamoto M, Tanaka H, Kon K (1992) A new antitumor antibiotic product, demethylchartreusin. Isolation and biological activities. J. Antibiot. 45: 875-878. https://doi. org/10.7164/antibiotics. 45.875

Chain EB (1958) Chemistry and biochemistry of antibiotics. Annu Rev. Biochem. 27: 167-222. https://doi.org/10.1146/annurev. bi.27.070158.001123

Chao JI, Kuo PC, Hsu TS (2004) Down-regulation of survivin in nitric oxide induced cell growth inhibition and apoptosis of the human lung carcinoma cells. J. Biol. Chem. 279: 20267-20276. https://doi. org/10.1074/jbc.M312381200

Chiang CC, Cheng MJ, Peng CF, Huang HY, Chen IS (2010) Anovel dimeric coumarin analog and antimycobacterial constituents from Fatoua pilosa. Chem. Biodivers. 7: 1728-1736. https://doi. org/10.1002/cbdv.200900326

Colquhoun A, Arnold M, Ferlay J, Goodman KJ, Forman D, Soerjomataram I (2015) Global patterns of cardia and non-cardia gastric cancer incidence in 2012. Gut. 64: 1881-1888. http://dx.doi. org/10.1136/gutjnl-2014-308915

Ferlay J, Steliarova-Foucher E, Lortet-Tieulent J, Rosso S, Coebergh JW, Comber H, Forman D, Bray F (2013) Cancer incidence and mortality patterns in Europe: estimates for 40 countries in 2012. Eur. J. Cancer 49: 1374-1403. https://doi.org/10.1016/j. ejca.2012.12.027

Hara S, Oya M, Mizuno R, Horiguchi A, Marumo K, Murai M (2005) Akt activation in renal cell carcinoma: contribution of a decreased PTEN expression and the induction of apoptosis by an Akt inhibitor. Ann. Oncol. 16: 928-933. https://doi.org/10.1093/annonc/ mdi182
Hodak K, Jakesová V, Dadák V (1967) On the antibiotic effects of natural coumarins. VI. The relation of structure to the antibacterial effects of some natural coumarins and the neutralization of such effects. Ceska Slov. Farm. 16: 86-91.

Hsu SL, Hsieh YC, Hsieh WC, Chou CJ (2001) Baicalein induces a dual growth arrest by modulating multiple cell cycle regulatory molecules. Eur. J. Pharmacol. 425: 165-171. https://doi.org/10.1016/ S0014-2999(01)01144-X

Iranshahi ME, Askari M, Sahebkar A, Hadjipavlou LD (2009) Evaluation of antioxidant, anti-inflammatory and lipoxygenase inhibitory activities of the prenylated coumarin umbelliprenin. DARU 17: 99103.

Janunger KG, Hafström L, Nygren P, Glimelius B (2001) SBU-group. Swedish Council of Technology Assessment in Health Care. A systematic overview of chemotherapy effects in gastric cancer. Acta Oncol. 40: 309-326. https://doi.org/10.1080/02841860121271

Jeon YJ, Jang JY, Shim JH, Myung PK, Chae JI (2015) Esculetin, a coumarin derivative, exhibits anti-proliferative and pro-apoptotic activity in G361 human malignant melanoma. J. Cancer Prev. 20: 106112. https://dx.doi.org/10.15430\%2FJCP.2015.20.2.106

Khursheed A, Jain V (2020) Medicinal research progress of natural coumarin and its derivatives. Nat. Prod. J. 10: 1. https://doi.org/10.2 174/2210315510999201102201552

Noguchi M, Earashi M, Minami M, Miyazaki I, Tanaka M, Sasaki T (1995) Effects of piroxicam and esculetin on the MDA-MB-231 human breast cancer cell line. Prostaglandins Leukot. Essent. Fatty Acids 53: 325-329. https://doi.org/10.1016/0952-3278(95)90051-9

Piao W, Yoo J, Lee DK, Hwang HJ, Kim JH (2001) Induction of G2/M phase arrest and apoptosis by a new synthetic anti-cancer agent, DW2282, in promyelocytic leukemia (HL-60) cells. Biochem. Pharmacol. 62: 1439-1447. https://doi.org/10.1016/S00062952(01)00796-1

Piller NB (1975) A comparison of the effectiveness of some antiinflammatory drugs on thermal oedema. Br. J. Exp. Pathol. 56: 554 560. PMID: 1222119

Portugal J (2003) Chartreusin, elsamicin A and related anti-cancer antibiotics. Curr. Med. Chem. Anticancer Agents 3: 411-420. https://doi. org/10.2174/1568011033482215

Pu L, Amoscato AA, Bier ME, Lazo JS (2002) Dual G1 and G2 phase inhibition by a novel, selective Cdc25 inhibitor 7-chloro-6-(2morpholin-4-ylethylamino)-quinoline-5,8-dione. J. Biol. Chem. 277: 46877-46885. https://doi.org/10.1074/jbc.M207902200

Shin E, Choi KM, Yoo HS, Lee CK, Hwang BY, Lee MK (2010) Inhibitory effects of coumarins from the stem barks of Fraxinus rhynchophylla on adipocyte differentiation in 3T3-L1 cells. Biol. Pharm. Bull. 33: 1610-1614. https://doi.org/10.1248/bpb.33.1610

Wall NR, O'Connor DS, Plescia J, Pommier Y, Altieri DC (2003) Suppression of survivin phosphorylation on Thr34 by flavopiridol enhances tumor cell apoptosis. Cancer Res. 63: 230-235. PMID: 12517802

Wang CM, Zhou W, Li CX, Chen H, Shi ZQ, Fan YJ (2009) Efficacy of osthol, a potent coumarin compound, in controlling powdery mildew caused by Sphaerotheca fuliginea. J. Asian Nat. Prod. Res. 11: 783-791. https://doi.org/10.1080/10286020903158964

Wang J, Lu ML, Dai HL, Zhang SP, Wang HX, Wei N (2015) Esculetin, a coumarin derivative, exerts in vitro and in vivo antiproliferative activity against hepatocellular carcinoma by initiating a mitochondrial-dependent apoptosis pathway. Bra\%. J. Med. Biol. Res. 48: 245-253. http:/ /dx.doi.org/10.1590/1414-431x20144074

Witaicenis A, Seito LN, Di Stasi LC (2010) Intestinal antiinflammatory activity of esculetin and 4-methylesculetin in the trinitrobenzenesulphonic acid model of rat colitis. Chem. Biol. Interact. 186: 211-218. https://doi.org/10.1016/j.cbi.2010.03.045

Yang D, Gu T, Wang T, Tang Q, Ma C (2010) Effects of osthole on migration and invasion in breast cancer cells. Biosci. Biotechnol. Biochem. 74: 1430-1434. https://doi.org/10.1271/bbb.100110 